\title{
Advertising Effectiveness: "Understanding the Value of Creativity in Advertising", a Review Study in India
}

\section{Pooja Sharma \\ Amrita School of Business, Bangalore Campus, Amrita University, India}

\begin{abstract}
In today's media landscape where it's very difficult to shape consumers attitude and intentions and move them to next level of buying process, advertisers find it even more difficult and challenging to break through the clutter of competing advertisement. The advertising industry has experienced dynamic changes over the last several decades. The changes have been good in terms of Technology advancement, Medium and more methods to attract consumers and on Creativity. This study represents how creativity impacted advertising, also understanding the value of creativity in advertising through the review of various literatures. The importance of creativity factor in advertising has got wide recognition by many researchers, practitioner, but there is a miss of true \& systematic research to define advertising creativity and how it relates to ad effectiveness. The review study discusses some campaigns that have left their strong impression on consumers. The presented review study tries to come up with some evidence of creativity by reviewing expert views, past literature in advertising, studied advertising campaign and marketing activities. The study discusses different forum on how creativity works, and what makes an ad to travel good or poorly. It summarized the value of creativity in advertising through Expert interviews, published material and related secondary data to understand the logic.
\end{abstract}

Keywords: Creativity, Advertising Strategy, Media, Consumer. 


\section{Introduction and Background}

It is known fact that there should be an element of creativity in an advertisement. This creativity is to create something new, unique, extremely attractive and appealing to the consumers. In fact, advertising itself is a creative process. It is the outcome of long term planning and hard work on the part of the copy writer \& creative director who prepares \& shapes the final copy of advertisement.

The objectives of this review study are to find out the role of creativity in advertising in Indian market. How creativity impacted the television ads. How advertisers can create distinctive effects through creative dimension especially in today's media landscape where advertisers find it even more challenging to break through the clutter of competing ads in order to shape consumers attitudes and intentions. One of the strategy alternative strategies to greater advertising spending may be more creative advertising. Understanding the fact that creative ideas do not come over night they are required to be developed through systematic thinking. Breakthrough ideas might appear to be instant or impulsive, but they are not. They are based on sound strategy, outstanding visuals and copy, and the correct application of timing and media. The art is in ensuring that all elements of communication work together so that the end result is more powerful and effective.

There are much bold evidences that significant changes faced by this industry. Some of these changes are good: big ideas, innovative partnerships, \& interesting new work, that show what advertising can do for brands. Advertising allows you to communicate a salient message to a large group of consumers faster than any other form of communication. It allows you to truly connect with your consumer; it gives you an opportunity to develop an ongoing relationship between the consumer and a brand. At its best, advertising will create a sense of urgency for the consumer, honest awareness and accurate that there are products, places, styles or sensibilities that cry out for attention or action. To do that there are various styles of advertising, a soft sell or a hard sell, a subtle approach or a blatant approach, an informative style, humor or a modern and edgy one. Style will always change: with the product or service you are selling; with the timing of the message and with the medium you are using. But important aspect is how you can engage your consumers to watch that Creative challenge you took with the blend of style. 
The important thing is finding the right balance between defining a good creative message and execution. The true craft is in identifying ways to interest consumers in what is being offered at the same time justifiable creativity. A creative strategy can put you on the right course, but in a world filled with distractions and clutter you must develop communications that capture consumer attention and interest. The key of delivering effecting creative message is the selling point in an interesting, non-contrived manner. Great advertising builds the brands and some advertising sells brands. Creativity makes advertisement popular among the consumers and motivates them to purchase advertisement specific product. The advertising message is received well by the target audience for follow-up action. Methodology: This study used a review study method to analyze the secondary data \& observations. David Ogilvy once quoted that "If it doesn't sell, it isn't creative." In this review study researcher has analyzed secondary data through the series of interview, expert comments, and live cases of various literatures and through live observations to understand the value of creativity in advertising. The review paper includes a various article, discussion and market insight from the leading marketers, creative director insights about how this promising form of advertising is constantly evolving.

The review paper concludes that creative plays extremely important role in advertising, while studying many ad campaigns it's been prove that how consumers have different reaction to unique ads. If Ad contains fun, humor, excitement, drama with the creative ingredient consumer will defiantly like the idea. It is an accepted fact that if you present your product, service, and idea in different manner you'll get high brand recall.

\section{Learning From Past: Some Heritage Brands and Recall Value}

In India there are some brands who have acquired distinct space in consumer mindset. These brands played very important role in initial marketing era, and managed to become an unforgettable brand for Indian households. From the initial years advertisers have used many different strategies to promote the products. There are classic television commercials caught consumers attentions and brands have endured the test of time. Colgate Toothpaste, Vimal, Pear's soap, Mysore Sandal Soap, Woodward's Gripe Water, Dabur India, Amrutanjan balm, Vicco, Pond's, Hindustan Unilever's Surf, Amul from Amul India and Prestige Pressure Cooker are symbols of heritage brands of India. Some of these brands are represent the Indian 
culture. Sometimes the brand relies heavily on product and price features, rather than advertising creativity.

The recalled values of these heritage brands in India are higher, than today's brands, the famous Colgate Toothpaste's "Surkasha chakra" (protective cycle) Vicco Cream's jingle concentrating on herbal benefits "Vicco turmeric nahi cosmetic" or the classic advertisement of Hindustan Unilever's Surf, where well known character "Lalita Ji" represents middle class women of India, gives Advice that "Surf ki khariddari mai hi samjhdari hai"(translate as, it makes sense to buy Surf), she became iconic figure overnight in Indian middleclass households.

Bajaj Auto with it all time hit tagline 'Hamara Bajaj', or it be Lux with tagline "filmi sitaron ka saundarya sabun", (translate as Beauty soap for film stars) \& Dalda-vanaspati was a impressive success and ruled the perch during its time, the unforgettable Liril campaign, the ad was all about waterfalls, sparkler water and the girl splashing water in total abandon singing "la la la la laaa". The ad was major success \& very much appreciated, at the same time it became the highest selling premium toilet soap in a period of two years. Most of the these Heritage brands appeal to many age groups, probably the product /brands is what used by one generation to another generation and continued to current generation, but understanding the success mantra behind these heritage brands can be tough but there are strong evidence stating towards their advertising appeal. The uniqueness of the campaign leads towards the high recalling. The frequency of television commercial was less and during that era there wasn't much competition and managed with only Indian National TV channel, "Doordarshan" these brands made their presence heavily on consumers, whereas Today's as a competitive market emerged in various categories i.e. soaps, shampoos, TV's fridge, Air conditioner and computers so did the media options to reach more people.

\section{The Campaigns: How Creativity Works?}

The current scenario focuses that advertising has altered in many ways, now advertising become more creative, and getting real. Creativity increases the brand value. There is enough evidence that value for a brand will be formed through creativity. With Pointing on India's phenomenal growth, it has become even more important for ad agencies and their clients to gear up together to meet challenges that come with such expansion. Creative ideas have no boundaries, Ideas can strike anytime. A successful \& great creative idea can give brands the 
required thrust to explore new heights. It is very important that with creativity involved in advertising it should not forget its basic agenda -of informing, convincing, and selling.

Creative advertising needs to intelligent, sharp, imaginative to the point and extremely catchy. It must motive people to purchase advertisement product. The message and appeal made should be able to make positive impact on the consumers. The creativity develops new useful ideas which further fulfill the desired requirement. Creativity should focus the attention of the customer on the product and he must feel the urge to have that product for same benefit. This suggests that creative advertising should be able to create demand for the product when it is introduced for the first time. Some of the distinct creative ads impacted hard.The advertising strategies are changing but should not leave question mark on the sustainability of creativity and also not to overlook consumer's intelligence

Another creative hit in Indian market is VODAFONE'S Creation "The Zoozoo", after successfully rebranding "Hutch to Vodafone" Vodafone Essar Limited, the India-based subsidiary of the global mobile network operator; Vodafone started expanding its presence in pan India. The new brand avatar of Vodafone is "Zoozoo" has created a new dimension of creativity. The Zoozoos advertising campaign highlighted the different value added service (VAS) offered by the company. This creative aspect got huge appreciation from the customer and they say you simply Love them and you just can't ignore them. The Zoozoos were everywhere, the creative ad series of 30 TVCs, were created by Ogilvy \& Mather for Indian Primer League of Cricket Season 2. The Zoozoos Coffee Mugs and T-shirts became instant hit in the market. Prior to this what Vodafone did to show the transition from Hutch to Vodafone, ad agency O\&M launched a rather direct, thematic ad showing the trademark pug in a garden, moving out of a pink colored kennel symbolizing Hutch, and making his way into a red one (the Vodafone color). A more energetic, chirpier version of the 'You and I' tune associated with Hutch, plays towards the end, as the super concludes, 'Change is good. Hutch is now Vodafone'.

Many times even public Awareness ads creates buzz and becomes click famous. The reveiew study of some of the public ads, result shows an ad where how a simple public awareness TVC shows a man manipulating a remote control toy car in an office set up. He receives a call and tries to answer it with continuing to manipulate the controls of the car. The car crashes. The ad message is very clear and gets across with no extra layers. Driving while 
talking on a mobile can cause accidents. The effects are visible. The campaigns that generate awareness about protective sex create high time awareness. Excellent example is "Condom, its Ok" ads by National Rural Health Mission (India) (National Aida control Organization) especially in the market like India.

If advertisers taking an absolute social cause to advertise it might lead to instant success in the market, review study suggested an example of 'IDEA' Cellular, The big ideas of Idea cellular campaign was worked really well in Indian market. It has been an interesting and almost 'off the track' ride for the brand belonging to the Aditya Birla Group, India. This cellular service used its brand name "idea" and real social issues to successfully showcasing its message in the consumer's mind spreading high level awareness. Some of the campaign shot in pure rural market setting. The campaign shows ugly reality in the social and political arena in India, it's very unique and different combination of creative aspect, "What an Idea sir ji" campaigns raised issues related to Caste wars, Education for all, Democracy, health Campaign, 'walk and talk'. The creativity of ideas worked well, while the team is well aware that most of the solutions it propagates in its ads may seem improbable, but at least it makes people think. The job is done if consumer also starts saying "what an Idea, Sirji!!.

There are many creative ads which made a direct entry into customer mind. Camlin India's Permanent Marker made a distinct effect on the consumer it leaves Lowe Lintas, devised a cool concept for the brand to advertise the product. This time this is Out of Home (OOH) advertising, the simple but eye-catching hoarding, with the three cut-out men having mechanically-backed moving limbs, trying to wipe off the words written in bright red, also displays the product - the permanent marker. The category of permanent markers are a very low involvement, in such scenario also ad agency had done clutter breaking, and at the same time, something that brings out the message clearly - here the message being 'permanent'." 
Table 3.1 Creative elements appeals in advertising review study (sample Size 100 ads)

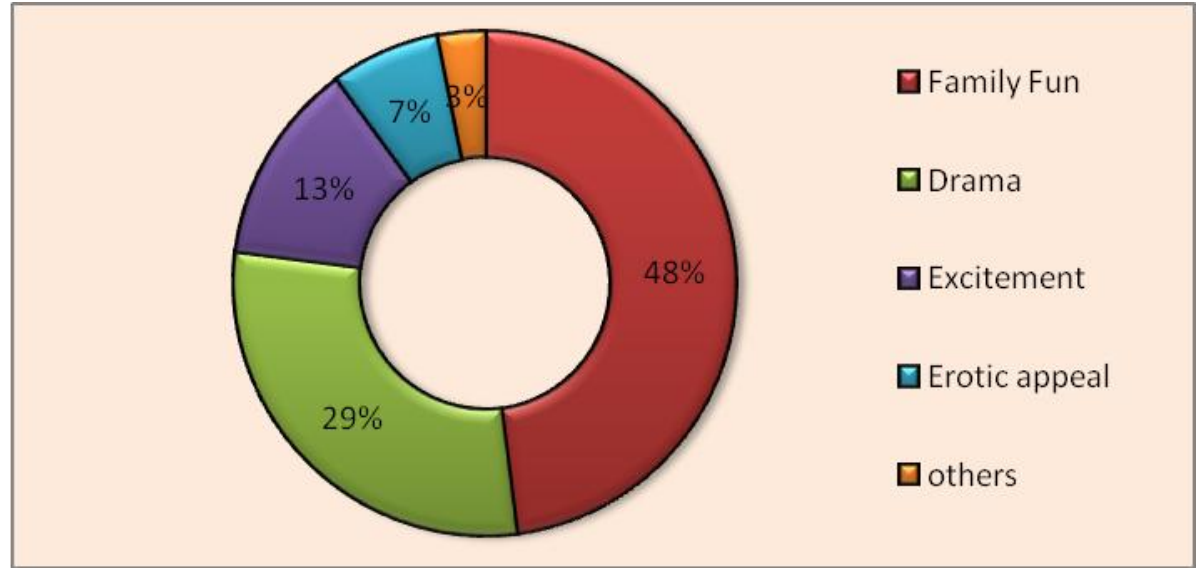

\section{What Makes Ad Successful; A Reality Check}

There are numerous factors play roles in determining whether advertisement travel well or poorly. Marketers need to test multiple markets to get a full understanding of an ad's likely effectiveness, but it becomes equally imperative to understand what it takes to beat the odds and create a truly Creative Advertising. The combination of creativity and the characteristics of ads that travelled well are, Children, Celebrities, Music, Humor and Emotions.

In India presence of Celebrities makes a big difference and this can work across markets. True to the phenomena that the famous celebrity can contribute to an ad travelling well but the ultimately success comes down to the power of good copy.

Humor, this word will now be associated with advertising for a long time to come. Humor can work greatly well, probably because it was cracked not long ago by the advertising fraternity, Or probably because the otherwise fretting Indian audience feels largely pepped up with humor in ads, and therefore, there are more chances of an ad acquiring mind space. Whatever be it, it's a formula which now everybody is trying hands on. Some ads are surely worth the effort. Particularly when it comes from visual and music, the examples can be 'Happydent white', and the great 'Amul butter' print series with 'Amul girl', 'Fevicol' ads, 'Mentos', Vodafone ad

Children are one of the key prominent features in ads and can be seen in every fourth advertisement. They are certainly great help for an ad to do well. But is it only the cuteness that adds to creative aspect? The child's simplicity, instant reaction and unique perspective 
towards the ads make changes. There are many examples where kids played important role in commercial and that leads to high success of the ads. An excellent example is "Dirt is Good or 'Daag Achche Hai"' ad for Surf Excel, in which a brother "fights" the mud his sister fell into. And the recent on which shows a little boy pretending to be a dog in order to make his teacher, who has just lost her dog, smile. Of course, in the process his white uniform gets mud spattered and totally worthy of a Surf Excel wash. This one from Lowe Lintas tugs the heart strings. This campaign sticks to its 'Daag Achche Hai' premise. Bank of India showing kid with piggy bank is yet another creative scoop.

At the same time advertising that generates an emotional response also has its own benefit, like it can help generate engagement and memorability and it can help the emotions transfer to the brand shaping the brand perception. Dove's real beauty campaign is perfect example.

\section{Creative Advertising: Is There A Strong Need In Market:}

Most brands in the same category deliver more or less the same functional benefits and answer the same needs of the consumers. With so many products on the market having the same function, the only way to position a product, service, or company differently from anything else in the same category is through creative development in advertising.

Today traditional advertising is losing its sheen. The biggest problem with traditional media is that consumers today have lots of choice for ad avoidance. The fragmentation is very high and there is very less scope of customized message for all. The Indian consumer has changed if we focus on this issue there is a lot more on the menu to choose from. Now the message unlike the past is no longer a one way process. But public opinion is far more mobilized, they have immediate platform for expression.

The expert believes that the creativity in advertising could never exist in isolation without a context. The success of final product completely depends on empathy and the relevance of message it intends to deliver. The trigger for ideas and insights must necessarily come from the environment.

The new millennium is decade old now, advertising, which is about creating demand, has undergone a complete transformation. Many things have changed and many things have 
stayed exactly the same in this industry. The media agencies have witnessed the tremendous growth in skills set. If one critically analyze, "advertising reflects the mood of the times. The simplistic inform-persuade-sell mode worked beautifully for a long time but once communication became sophisticated, technology entered, there was a paradigm shift. Multitasking became the order the day. It is not uncommon to see today's kids on the mobile while hitting the net, right? So in this age of Youtube, Twitter and Facebook, advertising content has to keep pace. It can't be as direct, naïve and simplistic as it once was. The new-age consumer would dismiss it, straightaway." For hard-core information and details about products and services that are in the hi-ticket category, the internet provides it all; one doesn't have to completely depend on advertising. So the job of advertising today is to primarily push the brand in an endearing fashion that triggers the recall factor, and examples discussed indicates that 'creativity' stored better recall value.

\section{Conclusion \& Implications}

Advertising business involves people \& creative advertising is one that sells through people's efforts, and appropriate market demand. If you create the healthy environment for creative people with right kind of required information, they can genuinely create great \& saleable advertising. Advertising people bond together as a 'team' not as individual, Therefore, creative advertising that actually sells in the market and live a hard impression in mind is the result of 'team work.' In advertising business creativity resulting from great team efforts, effective idea and communicate exactly same to the audience, these are the key factors in successful advertising campaigns. The Ad agencies must have hunger for these elements and strive for them.

There are many ads different product, categories, but how many of them were able to differentiate themselves from other? With creative ads they can certainly communicate it differently so as to create a distinct brand image in the minds of the consumer,"

There is great hunger from consumer's side they wanted to see things differently and its advertiser's responsibility to attract and engaged the consumers, they remember and memorize the creative ads than the product. Marekters needs to understand the various dimension of advertising creativity is important. To fully understand creativity, one would 
need to expose what factors are generally held to comprise it, and these some dimensions could be Novelty, Meaningfulness, Well Craftiness, Positivity, and Humor.

\section{References}

Chintala Medha (2006), "Heritage Brands Building and Repositioning Them” available at http://www.indianmba.com/Faculty_Column/FC270/fc270.html (accessed May 8 2010)

Joshi D. (2007), India calling: Vodafone's Strategy, unplugged available at http://www.afaqs.com/perl/news/story.html?sid=19184_India+calling:+Vodafone\% E2\%80\%99s+strategy+unplugged (accessed May 6 2010)

Joshi, Devina (2010), 'Rewind 2009: The highs and lows of Advertising', available at http://www.afaqs.com/perl/nrews/story.html?sid=25929 (accessed May 15 2010)

Joshi, Devina, (2009), 'The idea of idea', The Brand Reporter July 09, pp 32-34

Lethagen, H. and Modig E.(2008), ‘Unbundling creativity', master thesis Consumer Marketing May 2008

Mathias Lloyd (2010),"Advertising -Big Idea, "Has advertising lost the plot" available at "http://www.4psbusinessandmarketing.com/22042010/storyd.asp?sid=3620\&pageno $=1$ (accessed May 15 2010)

Moulee Shiv (2010), ‘The advertiser's India: one country or Many? Article @ Millward brown 2010

Sen, Gullu (2009), how advertising has changed: 'the instinct to heard still exists, now it's in electronic media' The Brand Reporter, Oct 2009, pp 16

Sheehan Kim Bartel, Morrison K. Deborah (2009) 'The creativity challenge: media confluence and its effects on the evolving advertising industry', Journal of interactive advertising, Vol 9 no 2 pp 40-43

Souza, Lynn De (2009), how advertising has changed: 'Media agencies have grown both in scale and skill' The Brand Reporter, Oct 2009, pp 18

Suneja, Sameer (2009), how advertising has changed: 'Traditional advertising is losing its sheen' The Brand Reporter, Oct 2009, pp 20 